\title{
Sulfated titania as additive in Nafion membranes for water electrolysis applications
}

\author{
S. Siracusano ${ }^{1}$, V. Baglio ${ }^{1}$, I. Nicotera ${ }^{2}$, L. Mazzapioda ${ }^{3}$, A.S. Aricò $^{1}$, S. Panero ${ }^{3}$, M.A. Navarra ${ }^{3, *}$ \\ ${ }^{1}$ CNR-ITAE, Via Salita S. Lucia sopra Contesse 5, 98126 Messina, Italy \\ ${ }^{2}$ Department of Chemistry and Chemical Technologies, University of Calabria, Via P. Bucci, 87036 Rende (CS), Italy \\ ${ }^{3}$ Department of Chemistry, University of Rome "La Sapienza", P.le Aldo Moro 5, 00185 Roma, Italy \\ "corresponding author: mariassutna.navarra@uniroma1.it
}

\begin{abstract}
Hydrogen produced by water splitting is a promising solution for a sustainable economy from renewable energy sources. With this respect, proton exchange membrane (PEM) electrolysis is one of the most suitable technologies, even though low cost, highly active catalysts and durable electrolyte membranes are still needed. Here we demonstrate the successful use of a nanocomposite, sulfated titania $\left(\mathrm{S}^{-\mathrm{TiO}_{2}}\right)$-added Nafion electrolyte coupled with home-made $\operatorname{IrRuO}_{x^{-}}$ based anode and commercial Pt cathode in lab-scale water electrolyzers. Superior electrolysis performances were found at $100{ }^{\circ} \mathrm{C}$ when comparing the hybrid electrolyte with undoped Nafion. Indeed, current densities of $4 \mathrm{~A} \mathrm{~cm}^{-2}$ and $3 \mathrm{~A} \mathrm{~cm}^{-2}$ were found at a terminal voltage of $2 \mathrm{~V}$ for the composite and plain membrane, respectively. Ex-situ conductivity measurements, as well as inoperando impedance spectra, were carried out, demonstrating the beneficial effect of the inorganic filler on membrane properties under practical operating conditions. NMR studies (PFG and relaxation time) corroborate the positive role of the nano-additive on the water retention capacity of the membrane, while the dynamic mechanical analysis shows that the hybrid membrane is stiffer and can resist to temperatures higher than undoped Nafion.
\end{abstract}

KEY WORDS: functionalized inorganic nano-additives; composite polymer electrolyte; water electrolyzers. 


\section{INTRODUCTION}

Water electrolysis via proton exchange membrane (PEM) cells is considered one of the most promising technologies for sustainable hydrogen production. The efficiency of this process is limited by the high overpotential of the oxygen evolution reaction (OER) [1]. $\mathrm{RuO}_{2}$ and $\mathrm{IrO}_{2}$ are among the few most active electrode materials; they have been the focus of detailed investigations [2-4]. However, the development of sufficiently stable anode materials with low OER overpotentials is still a challenge [5]. Although $\mathrm{RuO}_{2}$ is more active and cheaper than $\mathrm{IrO}_{2}$, it is prone to the electrochemical corrosion, which starts even before the OER onset [6] and prevents utilization of non-stabilized $\mathrm{RuO}_{2}$ for large scale PEM electrolysis. Bimetallic anodes based on $\mathrm{Ru}$ and Ir oxides combine the catalytic activity of $\mathrm{RuO}_{2}$ and the stability of $\mathrm{IrO}_{2}$ and have thus attracted considerable attention [2,7]. Our group has already demonstrated the successful use of bimetallic IrRuO ${ }_{2}$ compounds as effective catalysts able to reduce the OER overpotentials [8-10].

With respect to the electrolyte stability, membrane resistivity and controlled gas cross-over are important issues to be solved in PEM electrolyzers. Ohmic losses limit the maximum achievable current densities: with a thin membrane having good proton conductivity $\left(0.1 \pm 0.02 \mathrm{~S} \mathrm{~cm}^{-1}\right)$ [11] higher current densities can be achieved. Moreover, low gas crossover rate, provided by stable solid polymer electrolytes, yields hydrogen with high purity and allows for the PEM electrolyzer to work under a wide range of power input (economical aspect) [12]. Usually, commercial Nafion membranes from Dupont, based on a perfluorosulfonate (PFS) polymer, are ordinarily used due to their excellent chemical and thermal stability, mechanical strength and high proton conductivity $[13,14]$. However, a drawback of PFS membranes is that they are known to loose water [15], and thus ionic conductivity, at temperature around $100{ }^{\circ} \mathrm{C}$, which prohibits them from being used for higher temperature water electrolysis. The increase in the temperature of operation offers several advantages from thermodynamic, kinetic and engineering points of view. As an example, when the temperature is increased, the electrode kinetics will be enhanced and therefore the overpotentials will be reduced [16]. Composite or reinforced membranes with metal oxide particles (e.g., $\mathrm{SiO}_{2}$, $\mathrm{TiO}_{2}$, or $\mathrm{WO}_{2}$ ) allow an increase in the operating temperature and pressure of the electrolyzer [17]. These alternative composite membranes also decrease the cross-over of the gases through the membrane [18]. The high temperature operating condition is allowed by the water retention properties of the composite membrane due to the presence of inorganic hygroscopic fillers inside the polymeric matrix [19]. As a valid, more effective alternative to bare inorganic particles, solid acids or functionalized metal oxides have been proposed as additives in Nafion membranes, 
having the dual function of providing additional acid groups for proton conduction and enhancing water retention $[20,21]$. Due to their intrinsic super-acidity and tunable properties, sulfated metal oxides $\left(\mathrm{S}-\mathrm{MO}_{2}\right)$ are very attractive candidates as additives to form hybrid, nano-composite membranes having adequate performances at high temperature. Recently, in our laboratories sulfated zirconium [22-26], titanium [27-30], aluminum [31] and tin [32,33] oxides have been investigated as proton conductors or fillers in polymer systems. The potentiality of this family of compounds in PEMs for water electrolysis was proved by combining a $\mathrm{S}-\mathrm{ZrO}_{2} /$ Nafion membrane with $\mathrm{IrO}_{2}$ anode and $\mathrm{Pt}$ cathode [34]. In the latter work, the electrolyzer performance was compared to that of a commercial Nafion 115-based system, with superior characteristics being revealed at $100{ }^{\circ} \mathrm{C}$ for the composite membrane in terms of current densities and electrode/electrolyte interfacial properties. Also, S- $\mathrm{TiO}_{2} / \mathrm{Nafion}$ membranes were deeply investigated as electrolytes in PEM fuel cells, exhibiting very interesting features under targeted, critical operating conditions (i.e., $110{ }^{\circ} \mathrm{C}$ and $30 \%$ relative humidity) [30]. The improved performance achieved by $\mathrm{S}-\mathrm{TiO}_{2}$-doped membranes, compared to bare Nafion, was ascribed to the peculiar properties of the inorganic additive. Indeed, sulfated titania is characterized by high surface acidity due to sulfate groups anchored in a bidentate way on the titania surface. The sulfation degree, in the order of $8 \mathrm{wt} . \%$, was found to be quite stable to drastic hydrolytic conditions [29]. Moreover, the round-shaped nanoparticles of $\mathrm{S}^{-\mathrm{TiO}_{2}}$, having an averaged diameter of about $8 \mathrm{~nm}$ with an anatase lattice, distributed very homogeneously within the polymer matrix, being incorporated into the hydrophilic domains of Nafion [30].

In the present work, an optimized anode electrocatalyst based on $\mathrm{IrRuO}_{\mathrm{x}}$ and sulfated titaniaadded Nafion electrolyte were considered, to demonstrate the applicability for PEM electrolysis of the new proposed cell configuration at the desired relatively high working temperature.

\section{EXPERIMENTAL}

\section{Synthesis procedures}

Sulfated titania nano-particles, having an anatase crystallographic phase, were obtained following a convenient 1-step sol-gel synthesis procedure already reported in our previous works [27]. Briefly, $\mathrm{H}_{2} \mathrm{SO}_{4}(0.5 \mathrm{M} ; 6.4 \mathrm{ml})$ was added to a mixture of titanium isopropoxide (12.5 ml, SigmaAldrich) and 2-propanol (100 ml, Sigma-Aldrich) in vigorous stirring. After 2 hours, the solution was filtered and calcined for 3 hours at $400{ }^{\circ} \mathrm{C}$. 
Undoped and $\mathrm{S}_{-} \mathrm{TiO}_{2}$-added membranes were prepared by a solvent-casting technique, starting from a Nafion 5 wt.\% solution (Ion Power Inc), where solvents (water and alcohols) were gradually replaced by $\mathrm{N}, \mathrm{N}$-dimethylacetamide (Sigma Aldrich). When required, the inorganic particles were added to this Nafion suspension. The obtained mixtures, both loaded and undoped, were poured on a Petri dish. After a heating treatment at $100{ }^{\circ} \mathrm{C}$, dry membranes were obtained and hotpressed at $175{ }^{\circ} \mathrm{C}$ and $50 \mathrm{~atm}$ for 15 minute in order to improve their thermo-mechanical properties. The membranes were finally activated by immersion in boiling hydrogen peroxide (3\% $\mathrm{w} / \mathrm{w})$, sulfuric acid $(0.5 \mathrm{M})$ and water. After preparation, all the membrane samples were stored in distilled water. Membrane's thickness was measured in the dry state, immediately after the hotpressing procedure, resulting in the range of $100 \div 110 \mu \mathrm{m}$ for all the samples. In the present work, 5 wt.\% of $\mathrm{S}-\mathrm{TiO}_{2}$ with respect to dry Nafion content was considered, being this filler concentration the most performing one according to our previous investigations [29,30]. Composite and undoped Nafion membranes will be labelled as M5 and M0, respectively.

\section{$\underline{\text { Physico-chemical characterizations }}$}

The membranes total water uptake (WU) was evaluated at room temperature by the following equation:

WU $\%=\left[\left(W_{\text {hydrated }}-W_{\text {dry }}\right) / W_{\text {dry }}\right] \times 100$

(Equation 1)

The weight of fully hydrated membranes $\left(W_{\text {hydrated }}\right)$ was taken immediately after the final step of the activation procedure in boiling water. The weight of dry samples $\left(W_{\text {dry }}\right)$ was measured after the heating treatment at $100{ }^{\circ} \mathrm{C}$ and subsequent hot-pressing procedure, as described above for membranes preparation.

The ion-exchange capacity (IEC) of the membranes was evaluated by a titration method where the protons, exchanged by membrane samples equilibrated in $\mathrm{NaCl}$ aqueous solutions, were neutralized with $\mathrm{NaOH}(0.1 \mathrm{M})$. For both $\mathrm{WU}$ and IEC values, errors were evaluated with standard deviation of three different measurements.

Ex-situ, in-plane conductivity of membranes was measured by a DC operational four-electrode system, adopting a commercial cell (BT-112, Scribner Associates Inc) fitted between the anode and cathode flow field of a fuel cell test hardware (850C, Scribner Associates Inc.). This allows controlling the sample temperature and relative humidity $(\mathrm{RH})$. Humidification of the cell was set at $100 \%$ relative humidity $(\mathrm{RH})$ by bubbling the fed gas (i.e. nitrogen) through stainless steel 
cylinders incorporated in the compact system and containing distilled water. DC measurements, for the evaluation of membrane resistance as the slope of a linear plot of voltage versus current, were realized by a potentiostat (885, Scribner Associates Inc.) connected to the fuel cell test system and operating under the integrated FuelCell ${ }^{\circledR}$ software.

NMR measurements were performed on a Bruker NMR spectrometer AVANCE 300 Wide Bore working at $300 \mathrm{MHz}$ on ${ }^{1} \mathrm{H}$. The employed probe was a Diff30 Z-diffusion $30 \mathrm{G} / \mathrm{cm} / \mathrm{A}$ multinuclear with substitutable RF inserts. The pulsed field gradient stimulated-echo (PFG-STE) method [35] was used to measure the water self-diffusion coefficients. The sequence consists of three $90^{\circ} \mathrm{rf}$ pulses $\left(\pi / 2-\tau_{1}-\pi / 2-\tau_{m}-\pi / 2\right)$ and two gradient pulses that are applied after the first and the third $\mathrm{rf}$ pulses, respectively. The echo is found at time $\tau=2 \tau_{1}+\tau_{m}$. Following the usual notation, the magnetic field pulses have magnitude $g$, duration $\delta$, and time delay $\Delta$. The attenuation of the echo amplitude is represented by the following equation:

$I\left(2 \tau_{1}+\tau_{m}\right)=\frac{1}{2} I_{0} \exp \left[-\frac{\tau_{m}}{T_{1}}-\frac{2 \tau_{1}}{T_{2}}-(\gamma g \delta)^{2} D\left(\Delta-\frac{\delta}{3}\right)\right]$

(Equation 2)

where $D$ is the self-diffusion coefficient. The used experimental parameters were gradient pulse length $\delta=1 \mathrm{~ms}$, time delay $\Delta=10 \mathrm{~ms}$, and the gradient amplitude varied from 100 to $800 \mathrm{G} \mathrm{cm}^{-1}$.

Longitudinal relaxation times $\left(T_{1}\right)$ of water were measured by the inversion-recovery sequence ( $\pi$ $\tau-\pi / 2)$. The uncertainty in D and T1 values measured in this conditions was estimate to be about $3 \%$, based both on repeatability of the measurements and accuracy of the fitting curves to the experimental points. Self-diffusion and $T_{1}$ measurements were conducted by increasing temperature step by step from 20 to $130{ }^{\circ} \mathrm{C}$, with steps of $20^{\circ} \mathrm{C}$, and leaving, for each step, the sample to equilibrate for about $15 \mathrm{~min}$. The NMR measurements were conducted on membranes swelled up to the saturation, i.e. at the maximum WU. Therefore, after swelling in water, the membrane is quickly dried with a paper tissue (to eliminate drops of water on the surface) and put inside a NMR tube ( $5 \mathrm{~mm}$ of diameter), and close with a cap. Actually, we use to insert also a small cap of Teflon inside the tube just $2-3 \mathrm{~cm}$ above the membrane in order to reduce the free volume available to the evaporated water and to minimize the evaporation from the membrane with increased temperature.

The viscoelastic behavior both of the undoped Nafion and the nanocomposite was quantified in terms of storage modulus $\mathrm{G}^{\prime}$ and loss factor $\tan \delta$. DMA measurements were made with a Metravib DMA/25 equipped with a shear jaw for films. Spectra were collected on dry membranes by 
applying a dynamic stress of amplitude $10^{-3}$ at $1 \mathrm{~Hz}$ in the temperature range between $25{ }^{\circ} \mathrm{C}$ and $200{ }^{\circ} \mathrm{C}$ with a heating and cooling rate of $2{ }^{\circ} \mathrm{C} \mathrm{min}^{-1}$.

Membrane-Electrode Assemblies (MEAs) preparation and electrolysis cell tests

Two membrane-electrode assemblies were realized by using bare (M0) and $\mathrm{S}-\mathrm{TiO}_{2} / \mathrm{Nafion}(\mathrm{M} 5$ ) membranes. The $\mathrm{Ir}_{0.7} \mathrm{Ru}_{0.3} \mathrm{Ox}$ electrocatalyst was prepared according to Ref. [9] and used for the oxygen evolution reaction for both MEAs. The catalyst was directly deposited onto one side of the membrane by a spray-coating technique. Inks was composed of alcohol dispersion of catalyst, Nafion ionomer solution (5\% Aldrich) and Ethanol (Carlo Erba); the anode catalyst loading was 1.5 $\mathrm{mg} \mathrm{cm}{ }^{-2}$. The ionomer content in the anode layer was $20 \mathrm{wt} . \%$. A Ti fiber mesh (Bekaert Toko Metal Fiber Co.) was used as the backing layer. A commercial 30\% Pt/Vulcan XC-72 (E-TEK, PEMEAS, Boston, USA) was used as the catalyst for the $\mathrm{H}_{2}$ evolution. The cathode electrode was prepared by directly mixing in an ultrasonic bath a suspension of Nafion ionomer in water with the catalyst powder. The obtained cathode paste was painted on carbon cloth backings (GDL ELAT from E-TEK) with a Pt loading of $0.5 \pm 0.1 \mathrm{mg} \mathrm{cm}^{-2}$. The ionomer content was $33 \mathrm{wt} \%$ in the catalytic layer after drying. MEAs $\left(5 \mathrm{~cm}^{2}\right.$ geometrical area) were directly formed in the cell housing by tightening at $9 \mathrm{~N}$ m using a dynamometric wrench.

$5 \mathrm{~cm}^{2}$ single cell electrolyzer performances were evaluated at different temperatures $\left(80^{\circ}\right.$ and $100^{\circ} \mathrm{C}$ ) under atmospheric pressure. Deionized water was pre-heated the same cell temperature and supplied by a pump at a flow rate of $4 \mathrm{ml} \cdot \mathrm{min}^{-1}$ to the anode compartment. The water temperature was maintained at the same temperature of the cell by proper heat supply. Polarization curves and electrochemical impedance spectroscopy (EIS) were carried out by an Autolab PGSTAT 302 Potentiostat/Galvanostat equipped with a 20 A booster (Metrohm) instrument. The impedance measurements were performed under potentiostatic control at $1.5 \mathrm{~V}$ in a frequency range of $20 \mathrm{kHz} \div 0.1 \mathrm{~Hz}$ by frequency sweeping in the single sine mode, with a signal amplitude of the sinusoidal excitation equal to $0.01 \mathrm{~V}$.

\section{RESULTS AND DISCUSSION}

Membranes' intrinsic properties in terms of IEC and WU are reported in Table 1. Here, another important parameter, that is the number of water molecules per unit of acidic site $(\lambda)$, derived by the ratio between $\mathrm{WU}$ and IEC, is also displayed. 


\begin{tabular}{ccccc}
\hline Membrane & Sample acronym & IEC, meq g-1 & WU, \% & $\boldsymbol{\lambda}$ \\
\hline Nafion & M0 & $0.97 \pm 0.02$ & $33.7 \pm 1.4$ & $19.3 \pm 0.8$ \\
Nafion / S-TiO2 $5 \mathrm{wt}^{2} \%$ & $\mathrm{M} 5$ & $0.82 \pm 0.01$ & $34.8 \pm 1.8$ & $23.5 \pm 1.3$ \\
\hline
\end{tabular}

Table 1. Properties of the two membranes under investigation.

Even though the highly acidic $\mathrm{S}_{-} \mathrm{TiO}_{2}$ filler, $\mathrm{M} 5$ membrane presents a lower number of exchangeable protons. To be noted that the inorganic additive showed itself an estimated IEC of $1.08 \pm 0.03 \mathrm{meq} \mathrm{g}^{-1}[28]$. This high value is due to the sulfate groups (ca. $8 \mathrm{wt} . \%$ ), found to be strongly bonded on the titania surface. Indeed, after drastic hydrolytic treatment of $\mathrm{S}-\mathrm{TiO}_{2}$ powder in boiling water, a certain content of sulfates was retained, proving the stability of the functionalized compound [29]. The reduction of the IEC value in M5 membrane was already observed by us in other similar systems [32] and attributed to the increased density of the composite sample due to the ceramic powder. Anyhow, the possibility of strong filler-to-polymer functional groups interactions, reducing the availability of protons to be exchanged during our evaluation procedure, can not be excluded. Nevertheless, a small positive effect of the inorganic additive on the ability of the membranes to absorb and keep water entrapped into the polymer matrix is proved by the uptake results obtained upon swelling in liquid water. Indeed, WU is slightly higher in the case of the composite M5 membrane with respect to plain M0 Nafion. When accounting for the little differences of the quoted values, one has to consider that there is no general rationale available in explaining hydration properties of polymer electrolytes such as Nafion [36]. Overall, the combined effect of the smaller IEC and larger WU results in a higher $\lambda$ value for M5 compared to M0. Increased number of water molecules, bonded to the sulfonic polymer groups and/or to the sulfate functionalization of the additive, is an important feature for effective proton conduction. It is worth noticing that the $\lambda$ value obtained for $\mathrm{M} 0$ is comparable with data reported in literature for a commercial Nafion membrane swollen in water [36].

Proton conductivities of M0 and M5 samples, obtained by ex-situ in-plane measurements under $100 \% \mathrm{RH}$, are shown in Figure 1. 


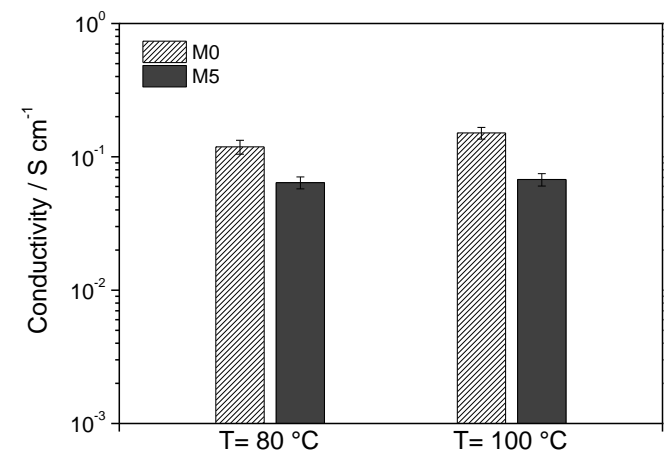

Figure 1. Proton conductivity of the undoped and $\mathrm{S}-\mathrm{TiO}_{2}$-added membranes under $100 \% \mathrm{RH}$.

Apparently under fully humidified conditions undoped Nafion shows larger conductivities compared to the composite membrane. Similar behaviors have been also reported by other authors $[37,38]$ and was already observed by us when evaluating proton conductivities of $\mathrm{MO}$ and M5 samples from impedance spectra recorded under fuel cell operations [30]. This result is certainly related to the alteration of the WU, IEC and, as a consequence, of the hydration number $\lambda$ for the composite membrane compared to the additive-free one [39]. As discussed above, M5 sample has larger WU and smaller IEC with respect to recast Nafion. Clearly, the higher number of exchangeable protons for undoped Nafion results in enhanced conductivity. However a direct relation between the amount of absorbed water and the ionic conductivity cannot be assumed since the proton mobility within the membranes depends also by the status of water, i.e. by electrostatic interactions and confinement effects inside the hydrophilic pores. In the case of the titania nanocomposite membranes, our previous studies demonstrated that the ratio between bound and free water in the matrix depends on the filler loading and the percentage of free-water was always higher in the nanocomposites respect to the recast Nafion [28]. Overall, conductivity values of about $10^{-1} \mathrm{~S} \mathrm{~cm}^{-1}$, obtained for both M0 and M5 samples, are suited for practical operation. Finally, a small conductivity increase was observed for both membranes when passing from 80 to $100{ }^{\circ} \mathrm{C}$, this addressing their applicability in electrolysis cells working at relatively high temperature.

The polarization curves of two cells, working under atmospheric pressure at $80^{\circ} \mathrm{C}$ and $100{ }^{\circ} \mathrm{C}$ and differing for the electrolyte material (i.e., undoped Nafion or composite $\mathrm{S}$ - $\mathrm{TiO}_{2}$-added membrane), are shown in Figure 2.
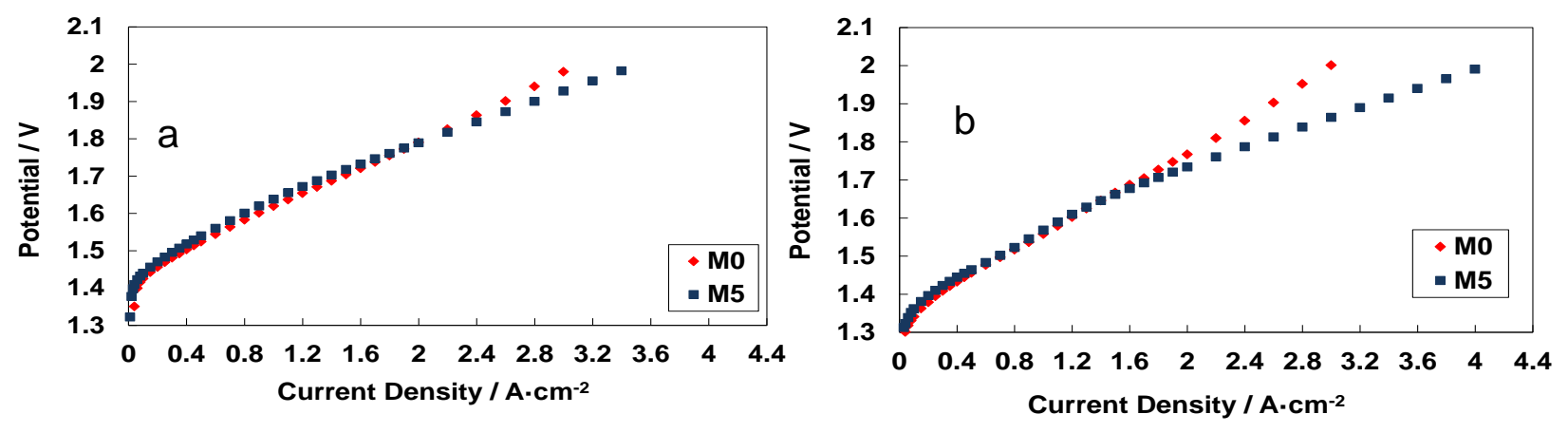
Figure 2. Polarization curves for two PEM electrolyzers, adopting undoped Nafion (MO) and composite S-TiO $\mathrm{S}_{2}$-added

(M5) membranes, under atmospheric pressure and working temperature of a) $80^{\circ} \mathrm{C}$ and b) $100{ }^{\circ} \mathrm{C}$.

A similar trend for the two cells under comparison is observed independently from the temperature value. Indeed, the current onset in the activation region is always more favorable for the cell with plain Nafion, whereas at higher voltages enhanced performances are associated to the composite $\mathrm{M} 5$ membrane. This increased behavior related to the $\mathrm{S}^{-\mathrm{TiO}_{2}}$-added system is much more pronounced when temperature raises, with current density as high as $4 \mathrm{~A} \mathrm{~cm}^{-2}$ at the terminal voltage for the M5 cell. Under such condition at $100^{\circ} \mathrm{C}$, a little change in the slope of the polarization curve at intermediate current densities (i.e., Ohmic region) is noticed for the composite membrane-based cell. This phenomenon needs to be better elucidated but on a first attempt it could be due to the presence of the functionalized inorganic filler dispersed in the polymer matrix, which produces a mixed proton conduction mechanism (i.e. assisted by both water molecules and additive particles) and is activated by the temperature and current flowing (see the impedance analysis reported below) [40]. Finally, it is worth noticing that almost unchanged values of current density are observed at $2 \mathrm{~V}$ for the cell with undoped Nafion when passing from 80 to $100{ }^{\circ} \mathrm{C}$. On the contrary, the beneficial highly welcome effect of temperature, on the cell adopting the composite membrane, results in a relative increment of final current densities of about $17 \%$.

To further analyze the different behavior of the two systems, in-situ electrochemical impedance spectra were recorded under cell polarization of $1.5 \mathrm{~V}$. The results in the form of Nyquist plots are displayed in Figure 3.
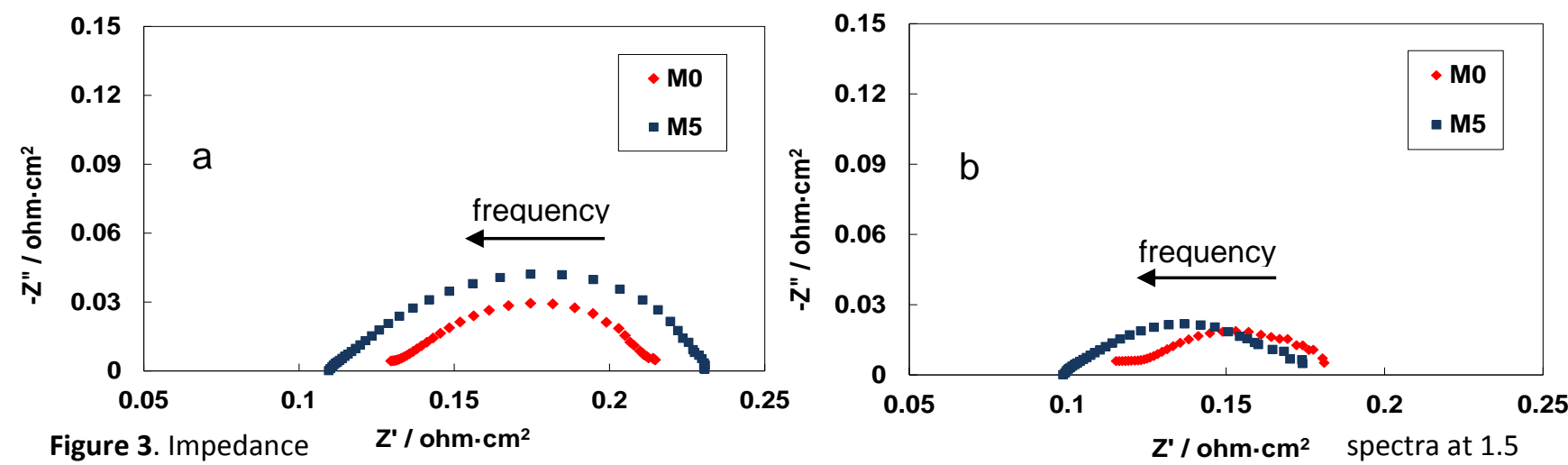

V for two PEM electrolyzers, adopting undoped Nafion (MO) and composite S- $\mathrm{TiO}_{2}$-added (M5) membranes, under atmospheric pressure and cell temperature of a) $80^{\circ} \mathrm{C}$ and b) $100{ }^{\circ} \mathrm{C}$. Frequency range: $20 \mathrm{kHz}-0,1 \mathrm{~Hz}$.

Series resistances, attributed to Ohmic overpotentials and mainly due to the electrolyte component, are taken from the high frequency intercept on the real axis of the impedance $\left(Z^{\prime}\right)$ in 
the Nyquist plot. Non-ohmic polarization resistances, due to the activation overpotentials at the electrodes, are taken as the difference between the extrapolated low frequency intercept and the series resistance. The polarization resistance is lower for the $\mathrm{MO}$-based cell, especially at $80{ }^{\circ} \mathrm{C}$, this accounting for its enhanced behavior in the activation region discussed above. It can be speculated that a better electrode-electrolyte interface is achieved by the use of plain Nafion. Nevertheless, an impressive improvement of the polarization resistance in the M5 cell is obtained upon temperature increase, this highlighting better electrode kinetics and enhanced interfacial processes at $100^{\circ} \mathrm{C}$ for the quoted system.

With respect to the series resistances, lower values are observed for the M5 cell at both temperatures and can be related to improved electrolyte conductivity, as the two M0 and M5 membrane samples have comparable thickness. This finding is apparently in contrast to the conductivity results obtained by ex-situ in-plane measurements. Our explanation is that, under electrolyzer operating conditions, with liquid water fed to the cell, proton mobility is enhanced and driven by the current flow, finally activating the effect of the acidic filler.

The complex role of the nano-additive on the proton dynamics in composite membrane was also addressed by ${ }^{1} \mathrm{H}-\mathrm{NMR}$ spectroscopy.

Figure 4 shows the proton self-diffusion coefficients (a) and the spin-lattice relaxation times (b) of the two membranes, M0 and M5, swelled at the saturation conditions. Concerning the diffusion, differently from the ionic conductivities, these type of measurements are conducted in absence of any gradient (electric, concentration, temperature, etc.), at the equilibrium of the system, therefore, they allow us to have information about the molecular dynamics of water confined in the hydrophilic membrane pores. During these measurements the sample is not supplied of other humidity if not that derived from the water absorbed during the swelling $[41,42]$. Therefore, as we can observe, the water diffusion increases by heating due to the thermal energy but, over a certain temperature, it decreases as a consequence of the strong water evaporation. This behavior can be easily clarified considering that: i) the self-diffusion coefficient measured at each temperature represents a weighted average between $D$ of bound water and of bulk-like water (or free water); ii) the evaporation of the water reasonably affects the bulk-like water, because not involved in electrostatic interactions, therefore, the contribution resulting from the bound water grows, and D decreases. However, while for $\mathrm{MO}$ such fall starts just above $80^{\circ} \mathrm{C}$, for the composite M5 it is shifted $20^{\circ} \mathrm{C}$ over, i.e. above $100{ }^{\circ} \mathrm{C}$. At this temperature the self-diffusion coefficients are $1.14 \times 10^{-5} \mathrm{~cm}^{2} \mathrm{~s}^{-1}$ and $2.28 \times 10^{-5} \mathrm{~cm}^{2} \mathrm{~s}^{-1}$ for M0 and M5, respectively. 
Further information about the local environment and dynamics of the water molecules can be obtained from the analysis of the spin-lattice relaxation times, T1, property that reflects short range motions (including both translation and rotation on a timescale comparable to the reciprocal of the NMR angular frequency, $\approx 1 \mathrm{~ns})$. Larger T1 implies more facile molecular movements. For both samples we observe a behavior vs temperature similar to that obtained for the diffusion. Indeed, the nanocomposite shows higher relaxation times than undoped Nafion above $100{ }^{\circ} \mathrm{C}$, confirming that local molecular movements are favored at higher temperatures, therefore, both $\mathrm{D}$ and $\mathrm{T} 1$ demonstrate that the addition of highly acidic sulfated- $\mathrm{TiO}_{2}$ improves water-retention capacity of the membrane. This finding, together with results from the electrolysis cell, both polarization tests and impedance spectra, demonstrates the role of the additive in governing water dynamics and proton mobility under high temperature operations.
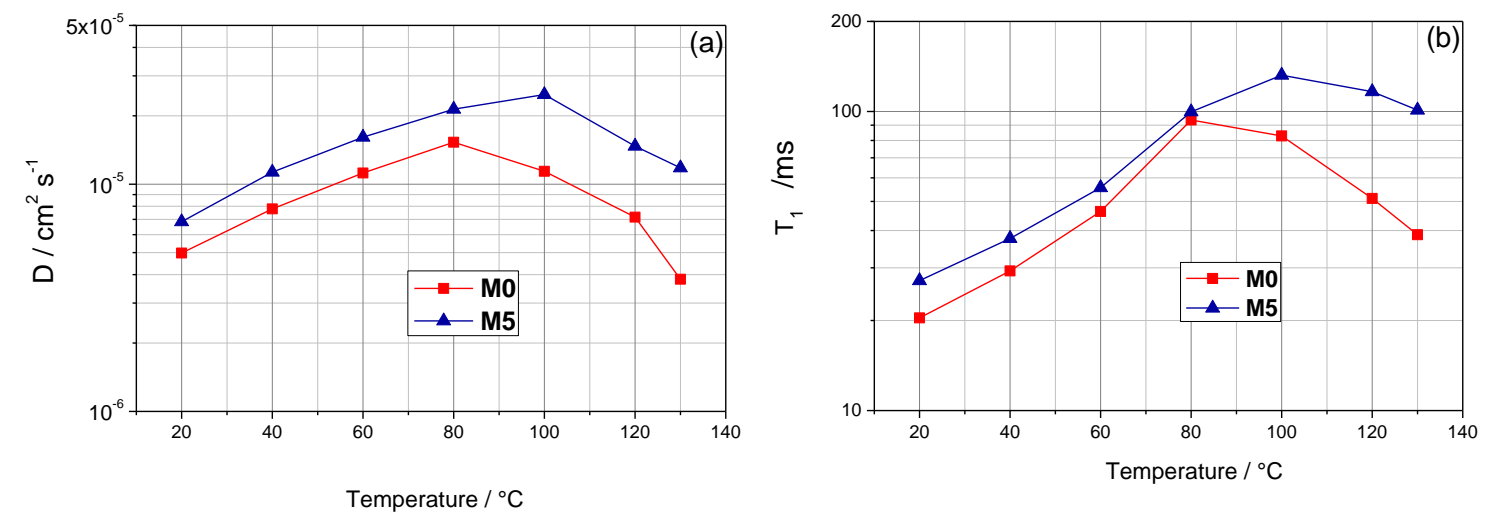

Figure 4. Temperature dependence of (a) Self-diffusion coefficients and (b) spin-lattice relaxation times of water confined in $\mathrm{M} 0$ and $\mathrm{M} 5$ membranes, from 20 up to $130^{\circ} \mathrm{C}$. The magnitude of the error is $\pm 3 \%$.

Finally, the mechanical properties of the electrolyte membranes were investigated by Dynamic Mechanical Analysis (DMA). Figure 5 reports the temperature evolution of storage modulus of the undoped Nafion (M0) and the nanocomposite (M5). M0 membrane shows a small decreasing of the storage modulus during heating and a net slope's change above $100{ }^{\circ} \mathrm{C}$. Similarly, the nanocomposite displays this trend even if it is shifted at slightly higher temperature. This is more visible in the plot of the tan-delta that puts in evidence the typical $\alpha$-transition correlated with segmental motion of polymer backbone chains $[43,44]$. This relaxation temperature is about 143 ${ }^{\circ} \mathrm{C}$ in pristine $\mathrm{MO}$ and reaches $152{ }^{\circ} \mathrm{C}$ for $\mathrm{M} 5$. This could be related to the presence of the nanoadditive within the pores of the Nafion membrane and to their interactions with the polymeric chains, increasing the stiffness of the membrane [45]. 

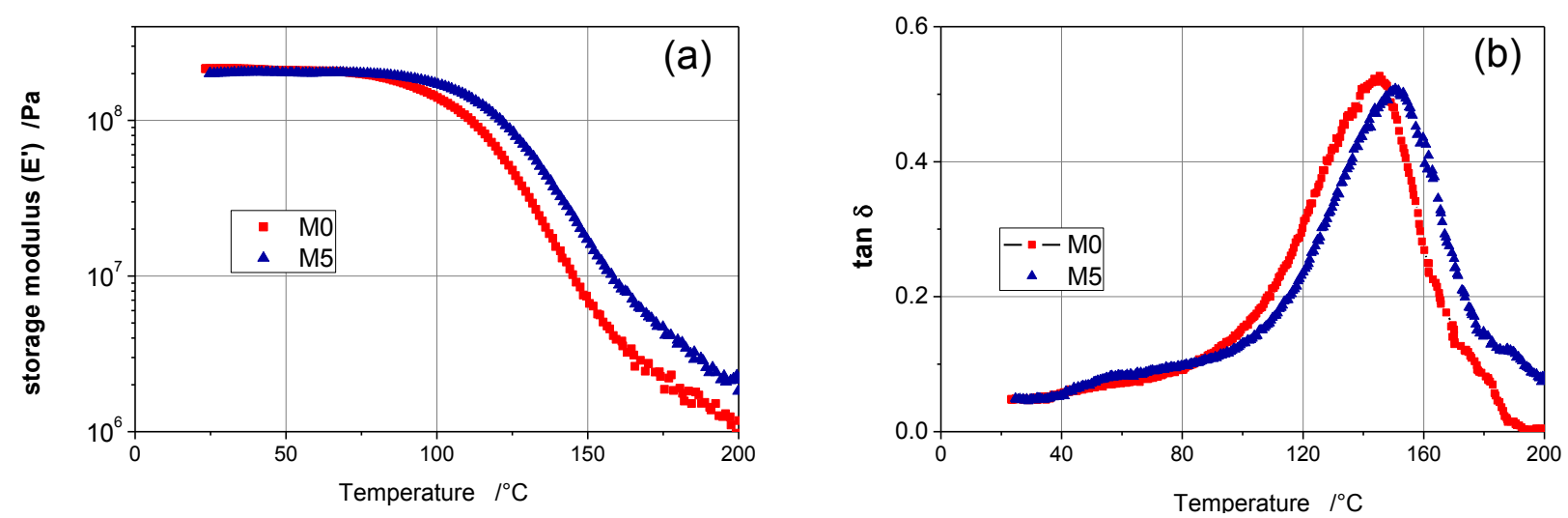

Figure 5. (a) Storage modulus, $\mathrm{E}^{\prime}$ and (b) tan-delta vs. temperature of $\mathrm{M} 0$ and $\mathrm{M} 5$ membranes, in the temperature range $20-200{ }^{\circ} \mathrm{C}$.

\section{CONCLUSIONS}

The effect of $\mathrm{S}-\mathrm{TiO}_{2}$ superacidic inorganic additive in a Nafion matrix was demonstrated in terms of membrane's peculiar properties (i.e. WU, IEC and $\lambda$ values), ex-situ proton conductivity and mechanical features. The complex dynamics of water and local molecular motions in doped and bare Nafion membranes were elucidated by ${ }^{1} \mathrm{H}-\mathrm{NMR}$. Despite little lower proton conductivity, obtained by $100 \%$ RH ex-situ in-plane measurements, for the nano-composite hybrid membrane, both water self-diffusion coefficients $(D)$ and spin-lattice relaxation times $\left(T_{1}\right)$ demonstrated that the addition of functionalized inorganic particles improves the high-temperature water-retention ability of the membrane. Electrolysis cell tests revealed an increment of current density with temperature (from 80 to $100{ }^{\circ} \mathrm{C}$ ) for the doped electrolyte, which was not observed in the case of plain Nafion. Both series and non-ohmic polarization resistances, achieved by in-situ impedance spectroscopy under cell polarization, were strongly reduced for the composite Nafion-based system upon temperature increase. Overall, the proposed $\mathrm{S}-\mathrm{TiO}_{2} / \mathrm{Nafion}$ membrane showed very interesting properties as electrolyte for intermediate PEM water electrolysis applications.

\section{ACKNOWLEDGMENTS}

M.A.N. acknowledges Sapienza University of Rome for the financial support to the project titled "Polymer electrolyte membrane water electrolysers: innovative, cost-effective electrocatalysts with enhanced durability" (2015, prot. C26A15HE93). CNR-ITAE authors acknowledge the financial support from HPEM2GAS project. This project has received funding from Fuel Cells and Hydrogen 
2 Joint Undertaking under grant agreement No 700008. This Joint Undertaking receives support from the European Union's Horizon 2020 research and innovation programme and Hydrogen Europe and N.ERGHY.

\section{REFERENCES}

[1] Katsounaros I, Cherevko S, Zeradjanin A.R, Mayrhofer K.J. Oxygen Electrochemistry as a Cornerstone for Sustainable Energy Conversion. Angew Chem Int Ed. Engl. 2014; 53:102-121.

[2] Fabbri E, Habereder A, Waltar K, Kötz R, Schmidt T.J. Developments and Perspectives of OxideBased Catalysts for the Oxygen Evolution Reaction. Catal Sci Technol. 2014; 4:3800-3821.

[3] Reier T, Pawolek Z, Cherevko S, Bruns M, Jones T, Teschner D, Selve S, Bergmann A, Nong H.N, SchlögI R, et al. Molecular Insight in Structure and Activity of Highly Efficient, Low-Ir Ir-Ni Oxide Catalysts for Electrochemical Water Splitting (OER). J Am Chem Soc. 2015; 137:13031-13040.

[4] Lettenmeier P, Wang L, Golla-Schindler U, Gazdzicki P, Cañ as N.A, Handl M, Hiesgen R, Hosseiny S.S, Gago A.S, Friedrich K.A. Nanosized IrOx-Ir Catalyst with Relevant Activity for Anodes of PEM Electrolysis Produced by a Cost-Effective Procedure. Angew Chem 2016; 128:752-756.

[5] Saveleva V.A, Wang L, Luo W, Zafeiratos S, Ulhaq-Bouillet C, Gago A.S, Friedrich K.A, Savinova E.R. Uncovering the Stabilization Mechanism in Bimetallic Ruthenium-Iridium Anodes for Proton Exchange Membrane Electrolyzers. J Phys Chem Lett 2016; 7:3240-3245.

[6] Hodnik N, Jovanovic P, Pavliš ič A, Jozinovič $B$, Zorko $M$, Bele $M$, Š elih V.S, Š ala M, Hocevar S, Gaberš ček M. New̌ Insights into Corrosion of Ruthenium and Ruthenium Oxide Nanoparticles in Acidic Media. J Phys Chem C 2015; 119:10140-10147.

[7] Over H. Surface Chemistry of Ruthenium Dioxide in Heterogeneous Catalysis and Electrocatalysis: From Fundamental to Applied Research. Chem Rev 2012; 112:3356-3426.

[8] Siracusano S, Baglio V, Van Dijk N, Merlo L, Aricò A.S. Enhanced performance and durability of low catalyst loading PEM water electrolyser based on a short-side chain perfluorosulfonic ionomer. Applied Energy 2017; 192:477-489. 
[9] Siracusano S, Van Dijk N, Payne-Johnson E, Baglio V, Aricò A.S. Nanosized $\operatorname{IrO}_{x}$ and $\operatorname{IrRuO} \mathrm{O}_{\mathrm{x}}$ electrocatalysts for the $\mathrm{O}_{2}$ evolution reaction in PEM water electrolysers. Applied Catalysis B: Environmental 2015;164:488-495.

[10] Siracusano S, Baglio V, Moukheiber E, Merlo L, Aricò A.S. Performance of a PEM water electrolyser combining an IrRu-oxide anode electrocatalyst and a shortside chain Aquivion membrane. Int J Hydrogen Energy 2015; 40 (42): 14430-14435.

[11] Slade S, Campbell SA, Ralph TR, Walsh FC. Ionic conductivity of an extruded Nafion 1100 EW series of membranes. Journal of the Electrochemical Society 2002; 149: A1556-64.

[12] Marcelo Carmo, David L. Fritz, Jürgen Mergel, Detlef Stolten. A comprehensive review on PEM water electrolysis. Int J Hydrogen Energy 2013; 38:4901-4934.

[13] Ursua A, Gandia L.M, Sanchis P. Hydrogen production from water electrolysis: current status and future trends. Proceedings of the IEEE 2012; 100:410-26.

[14] Goni-Urtiaga A, Presvytes D, Scott K. Solid acids as electrolyte materials for proton exchange membrane (PEM) electrolysis: Review. Int. J. Hydrogen Energy 2012;37:3358-72.

[15] Albertini V.R, Paci B, Generosi A, Panero S, Navarra M.A, Di Michiel M. In situ XRD studies of the hydration degree of the polymeric membrane in a fuel cell, Electrochem and Solid-State Letters 2004; 7:A519-21.

[16] Li Q.F, Pan C, Jensen J.O, Noye P, Bjerrum N.J. Cross-linked polybenzimidazole membranes for fuel cells. Chem Mater 2007; 19:350-2.

[17] Ornelas R, Baglio V, Matteucci F, Martina F, Ciccarella G, Zama I, et al. Solid polymer electrolyte water electrolyser based on Nafion- $\mathrm{TiO}_{2}$ composite membrane for high temperature operation. Fuel Cells 2009; 9:247-52.

[18] Antonucci V, Di Blasi A, Baglio V, Ornelas R, Matteucci F, Ledesma-Garcia J, et al. High temperature operation of a composite membrane-based solid polymer electrolyte water electrolyser. Electrochimica Acta 2008; 53:7350-6.

[19] Watanabe M, Uchida H, Seki Y, Emori M, Stonehart P. Self-humidifying polymer electrolyte membranes for fuel cells. Journal of the Electrochemical Society 1996;143:3847-52. 
[20] Aricò A.S; Baglio V, Di Blasi A, Creti P, Antonucci P.L, Antonucci V. Influence of the acid-base characteristics of inorganic fillers on the high temperature performance of composite membranes in direct methanol fuel cells. Solid State lonics 2003; 152:251-265.

[21] Ren S, Sun G, Li C, Song S, Xin Q, Yang X. Sulfated zirconia-Nafion composite membranes for higher temperature direct methanol fuel cells. J. Power Sources 2006;157:724-726.

[22] Navarra M.A, Croce F, Scrosati B. New high temperature superacid zirconia-doped Nafion composite membranes. J Mater Chem 2007;17:3210-3215.

[23] Navarra M.A, Abbati C, Scrosati B. Properties and fuel cell performance of a Nafion-based, sulfated zirconia-added, composite membrane. J. Power Sources 2008; 183:109-113.

[24] Navarra M.A, Abbati C, Croce F, Scrosati B. Temperature-dependent performances of a fuel cell using a superacid zirconia-doped nafion polymer electrolyte. Fuel Cells 2009; 9:222-225.

[25] D'Epifanio A, Navarra M.A, Weise F, Mecheri B, Farrington J, Licoccia S, Greenbaum S. Composite Nafion/sulfated zirconia membranes: Effect of the filler surface properties on proton transport characteristics. Chem Mater 2010; 22:813-821.

[26] Giffin G.A, Piga M, Lavina S, Navarra M.A, D'Epifanio A, Scrosati B, Di Noto V. Characterization of sulfated-zirconia/Nafion ${ }^{\circledR}$ composite membranes for proton exchange membrane fuel cells. J. Power Sources 2012; 198:66-75.

[27] Sgambetterra M, Panero S, Hassoun J, Navarra M. A. Hybrid membranes based on sulfated titania nanoparticles as low cost proton conductors. Ionics 2013;19:1203-1206.

[28] Nicotera I, Kosma V, Simari C, Ranieri G.A, Sgambetterra M, Panero S, Navarra M.A. An NMR study on the molecular dynamic and exchange effects in composite Nafion/sulfated titania membranes for PEMFCs. International Journal of Hydrogen Energy 2015; 40:14651-14660.

[29] Allodi V, Brutti S, Giarola M, Sgambetterra M, Navarra M.A, Panero S, Mariotto G. Structural and Spectroscopic Characterization of a Nanosized Sulfated $\mathrm{TiO}_{2}$ Filler and of Nanocomposite Nafion Membranes. Polymers 2016; 8, 68:1-13.

[30] Sgambetterra M, Brutti S, Allodi V, Mariotto G, Panero S, Navarra M.A. Critical Filler Concentration in Sulfated Titania-Added Nafion ${ }^{\text {TM }}$ Membranes for Fuel Cell Applications, Energies 2016; 9, 272:1-15. 
[31] Branchi M, Sgambetterra M, Pettiti I, Panero S, Navarra M.A. Functionalized $\mathrm{Al}_{2} \mathrm{O}_{3}$ particles as additives in proton-conducting polymer electrolyte membranes for fuel cell applications, Inter J Hydrogen Energy 2015; 40:14757-14767.

[32] Scipioni R, Gazzoli D, Teocoli F, Palumbo O, Paolone A, Ibris N, Brutti S, Navarra M.A. Preparation and characterization of nanocomposite polymer membranes containing functionalized $\mathrm{SnO}_{2}$ additives. Membranes 2014; 4:123-142.

[33] Brutti S, Scipioni R, Navarra M.A, Panero S, Allodi V, Giarola M, Mariotto, G. $\mathrm{SnO}_{2}$-Nafion nanocomposite polymer electrolytes for fuel cell applications. Int J Nanotechnology 2014; 11:882896.

[34] Siracusano S, Baglio V, Navarra M.A, Panero S, Antonucci V, Aricò A.S. Investigation of composite Nafion/sulfated zirconia membrane for solid polymer electrolyte electrolyzer applications. Intern J Electrochem Sci 2012; 7:1532-42.

[35] Tanner JE. Use of the stimulated echo in NMR diffusion studies. J Chem Phys. 1970, 52, 25236.

[36] Kreuer K.D. The role of internal pressure for the hydration and transport properties of ionomers and polyelectrolytes. Solid State lonics 2013; 252:93-101.

[37] Wu Z, Sun G, Jei W, Hou H, Wang S, Xin Q. Nafion ${ }^{\circledR}$ and nano-size $\mathrm{TiO}_{2}-\mathrm{SO}_{4}{ }^{2-}$ solid superacid composite membrane for direct methanol fuel cell. J Membr Sci 2008; 313:336-343.

[38] Rhee C.H, Kim Y, Lee J.S, Kim H.K, Chang H. Nanocomposite membranes of surface-sulfonated titanate and Nafion ${ }^{\circledR}$ for direct methanol fuel cells. J Power Sources 2006; 159:1015-1024.

[39] Zawodzinski T.A, Derouin C, Radzinski S, Sherman R.J, Smith V.T, Springer T.E, Gottesfeld S. Water Uptake by and Transport Through Nafion ${ }^{\circledR} 117$ Membranes J Electrochem Soc 1993; 140:1041-1047.

[40] Shen L, Sun Z, Chu Y, Zou J, Deshusses M.A. Novel sulfonated Nafion ${ }^{\circledR}$-based composite membranes with pillararene as selective artificial proton channels for application in direct methanol fuel cells, Inter J Hydrogen energy 2015; 40:13071-13079.

[41] Simari C, Potsi G, Policicchio A, Perrotta I, Nicotera I. Clay-Carbon Nanotubes Hybrid Materials for Nanocomposite Membranes: Advantages of Branched Structure for Proton Transport under Low Humidity Conditions in PEMFCs, J Phys Chem C. 2016; 120 (5):2574-2584. 
[42] Nicotera I, Simari C, Coppola L, Zygouri P, Gournis D, Brutti S, Minuto F.D, Aricò A.S, Sebastian D, Baglio V. Sulfonated Graphene Oxide Platelets in Nafion Nanocomposite Membrane: Advantages for Application in Direct Methanol Fuel Cells, J Phys Chem C 2014; 118:24357-24368.

[43] Stefanithis ID, Mauritz KA. Microstructural evolution of a silicon oxide phase in a perfluorosulfonic acid ionomer by an in situ sol-gel reaction. 3. Thermal analysis studies. Macromolecules 1990; 23:2397-2402.

[44] Teocoli F, Paolone A, Palumbo O, Navarra M.A, Casciola M, Donnadio A, Effects of water freezing on the mechanical properties of Nafion membranes, J Polymer Science, Part B: Polymer Physics 2012; 50:1421-1425.

[45] Rosero-Navarro N.C, Domingues E.M, Sousa N, Ferreira P, Figueiredo F.M. Protonic conductivity and viscoelastic behaviour of Nafion ${ }^{\circledR}$ membranes with periodic mesoporous organosilica fillers, Inter J Hydrogen energy 2014; 39:5338-5349. 